\title{
EVIDÊNCIAS CIENTÍFICAS ACERCA DO IMPACTO DAS MÍDIAS SOCIAIS NO ENFRENTAMENTO DA PANDEMIA DA COVID-19
}

SCIENTIFIC EVIDENCES ABOUT THE SOCIAL MEDIA IMPACT IN THE COPING OF THE COVID 19 PANDEMIC

DOI: http://dx.doi.org/10.16891/2317-434X.v8.e3.a2020.pp766-774

Recebido em: 06.07.2020 | Aceito em: 30.09.2020

\section{Alécia Hercidia Araújo*, Isabella Lins Silva, Rosely Leyliane dos Santos}

Universidade Regional do Cariri (URCA)

*E-mail: aleciaaraujo99@gmail.com

\section{RESUMO}

As Tecnologias de Informação e Comunicação (TIC's), em especial as mídias e as plataformas, são atores sociais importantes, sobretudo quando se trata das comunicações para prevenção de doenças em meio a uma emergência de saúde, como a atual pandemia por COVID-19. O objetivo deste estudo é descrever as evidências científicas acerca do impacto das mídias sociais para os usuários no enfrentamento da pandemia da COVID-19. Trata-se de uma revisão integrativa da literatura, realizada no período de junho a julho de 2020, nas bases de dados MEDLINE, LILACS e BDENF, utilizando-se os descritores "Mídias Sociais/Social media" e "Infecções por Coronavírus/Coronavirus infections". Os critérios de inclusão foram artigos completos disponíveis; nos idiomas português, inglês e espanhol; com ano de publicação em 2020. Os critérios de exclusão foram artigos repetidos e que não respondessem à pergunta norteadora. 0 processo de busca e seleção dos estudos ocorreu com a utilização do fluxograma PRISMA. Assim, 17 artigos compuseram a amostra, sendo 16 indexados na MEDLINE e um 1 na LILACS. Este estudo revelou potencialidades e desafios no que se refere ao impacto das mídias sociais frente à pandemia em progresso. A rápida disseminação e compartilhamento de informações em relação à prevenção da doença, além da adesão de diferentes públicos foram evidenciados como potencialidades advindas das mídias digitais. Contudo, despontaram-se que a sobrecarga de informações e a disseminação de Fake News, são os principais desafios. Sugere-se que novos estudos sobre a temática sejam realizados, pois esses são o principal meio de comunicação da atualidade.

Palavras-chave: Coronavírus; Disseminação de Informação; Saúde Global.

\section{ABSTRACT}

The Communication and Information Technologies (Tecnologias de Informação e Comunicação - TIC), media and platform in especial, are important social, agents especially in disease prevention communication in health emergency's as the actual COVID-19 pandemic. The objective of this study is to describe the scientific evidences about the impact of the social Medias in the users in the coping of the COVID-19 pandemic. It is a integrative review of the literature, made in the period of June to July of 2020, in the MEDLINE, LILACS and BDENF data base using the describers "Mídia Social/Social media" e "Infeç̧ões por Coronavírus/Coronavirus infections". The inclusion criterion was: complete text's avaliable; in portuguese; in english; and Spanish; with publication date of 2020; the exclusion criterion was repeated articles that not reply to the guiding question. The search and selection process in the study was made by the PRISMA flowchart utilization, so 17 articles composed the sample, even 16 being indexed in the MEDLINE and 1 in the LILACS. This study revealed potentials and challenges in the social media impact against the ongoing pandemic. The quick dissemination and share of information's about the disease prevention, beyond the adhesion of different publics were shown as potentials coming from the digital media. However, the information overload emerged, and the fake news dissemination are the main challenges against the pandemic by the social media. It is suggested that, new study`s about the thematic are made because this are the main communication way actually.

Keyword: Coronavirus; Information Dissemination; Global Health. 


\section{INTRODUÇÃOO}

$\mathrm{O}$ avanço tecnológico influenciou o modo de agir, pensar e se relacionar dos indivíduos. Segundo Silva e Soares (2018), a introdução de tecnologias na esfera social caracteriza-se como um fator relevante diante do conhecimento, divulgação e uso das Tecnologias de Informação e Comunicação (TIC's) nas distintas áreas sociais.

As TIC's são reconhecidas com sentido semelhante de tecnologias da informação (TI). Destarte, é um termo amplo que enfatiza a função da comunicação na tecnologia da informação moderna. Compreende-se que as mesmas equivalem a todos os recursos técnicos utilizados para proceder às informações e assessorar a comunicação (OLIVEIRA; MOURA; SOUSA, 2015).

Segundo França, Rabello e Magnago (2019), as mídias e as plataformas interagem e influenciam a sociedade. Além disso, são estratégias que se fazem presentes no cotidiano, não sendo consideradas meramente mediadores ou espaços distintos do dia a dia. Dessa forma, compreende-se o lugar estratégico que as mídias e plataformas digitais desempenham frente à rotina das pessoas.

Notificações eletrônicas chegam a todo momento, o toque do celular ecoa no aparelho auditivo exercendo o papel de anunciador; seja uma notícia, mensagem, foto ou vídeo. As informações são dinâmicas. A curiosidade pode superar qualquer outra atividade realizada no momento, pois em questão de minutos o conteúdo recebido é visualizado e uma nova informação é absorvida. Conforme o grau de relevância atribuída pelo receptor da mensagem eletrônica, a informação pode ser desconsiderada ou compartilhada para a ciência de outros indivíduos.

No dia 11 de março de 2020, a Organização Mundial da Saúde (OMS), reconheceu o Corona Virus Disease (COVID-19) como uma pandemia. Corona Virus Disease, traduzido para o português significa "Doença do Coronavírus" e com o número "19", escrito ao lado da sigla COVID, refere-se a uma nova doença causada pelo vírus SARS-CoV-2. Há evidências que os primeiros casos desta patologia foram no ano de 2019, em Wuhan, na China (WHO, 2020; FIOCRUZ, 2020). Informações, com e sem base científica a respeito da COVID-19, começaram a serem vinculadas nas mídias sociais, sendo disseminadas rapidamente.

Assim, justifica-se o desenvolvimento desta pesquisa para que se conheça qual a repercussão das mídias sociais no enfrentamento da pandemia pela COVID-19 que está em progressão, mesmo diante das medidas recomendadas e difundidas, pelas mídias sociais, para minimizar a transmissão e contágio pelo vírus. Neste sentido, é importante modelar a influência desses meios de comunicação na divulgação das informações em saúde. Assim, o objetivo deste estudo é descrever as evidências científicas acerca do impacto das mídias sociais para os usuários no enfrentamento da pandemia da COVID-19.

\section{METODOLOGIA}

Trata-se de uma revisão integrativa da literatura, realizada no período de junho a julho de 2020. A pergunta norteadora para subsídio à construção desta pesquisa foi: como as mídias sociais impactaram os usuários diante do enfrentamento da pandemia da COVID-19? Para tanto, seis etapas foram seguidas para a realização desta revisão: 1) Reconhecimento do tema e escolha da questão de pesquisa; 2) Pesquisa e triagem dos estudos; 3) Determinação das informações a serem extraídas dos estudos selecionados; 4) Avaliação dos estudos incluídos; 5) Interpretação dos resultados; 6) Exposição do método (MENDES; SILVEIRA; GALVÃO, 2019).

A primeira etapa de reconhecimento do tema e escolha da questão de pesquisa foi embasada em verificar a relevância da temática. Em prosseguimento, a segunda etapa constituiu a busca na base de dados através dos Descritores em Ciências da Saúde (DeCS) e Medical Subject Headings (MeSH), "Mídias Sociais/Social media"; "Infecções por Coronavírus/Coronavirus infections", combinados pelo operador booleano "AND", por meio da Biblioteca Virtual de Saúde (BVS) nas bases de dados Medical Literature Analysis and Retrieval System Online (MEDLINE), Literatura LatinoAmericana e do Caribe em Ciências da Saúde (LILACS) e Base de Dados em Enfermagem (BDENF).

Os critérios de inclusão utilizados foram: artigos completos disponíveis; nos idiomas português, inglês e espanhol; com ano de publicação em 2020, uma vez que a Organização Mundial da Saúde (OMS) decretou no dia 11 de março de 2020, o SARS-CoV-2 como uma pandemia. Os critérios de exclusão foram artigos repetidos e que não respondessem à pergunta norteadora. O resultado da busca totalizou um quantitativo de 102 artigos.

A terceira etapa da revisão consistiu na leitura preliminar de título e resumo dos estudos gerados pela busca na base de dados, sendo analisados por duas pesquisadoras de forma independente, resultando na seleção de trinta e três artigos. A quarta etapa, baseou-se na análise, composta pela leitura completa das publicações selecionadas. Ao final desta etapa, dezessete artigos foram incluídos para servir de aporte para a escrita desta pesquisa, sendo fichados indicando o título do artigo, autor(es) e a transcrição dos desfechos principais dos estudos.

A quinta etapa referente a interpretação dos 
resultados, destinou-se a compreensão das informações selecionadas através dos estudos, sendo relatados de maneira sintetizada e discutidos em duas categorias temáticas, a primeira sendo as potencialidades e a segunda, os desafios, ambas referentes as mídias sociais no enfrentamento da pandemia da COVID-19; que foram analisados de acordo com a literatura atual.
A última etapa, exposição do método, deteve a explanação das etapas percorridas, dos resultados obtidos, da discussão referente às informações relatadas. O processo de busca e seleção dos estudos desta revisão estão apresentados na Figura 1 por meio do fluxograma Preferred Reporting Items for Systematic Review and Meta-Analyses (PRISMA).

Figura 1. Fluxograma dos cruzamentos e resultados das buscas
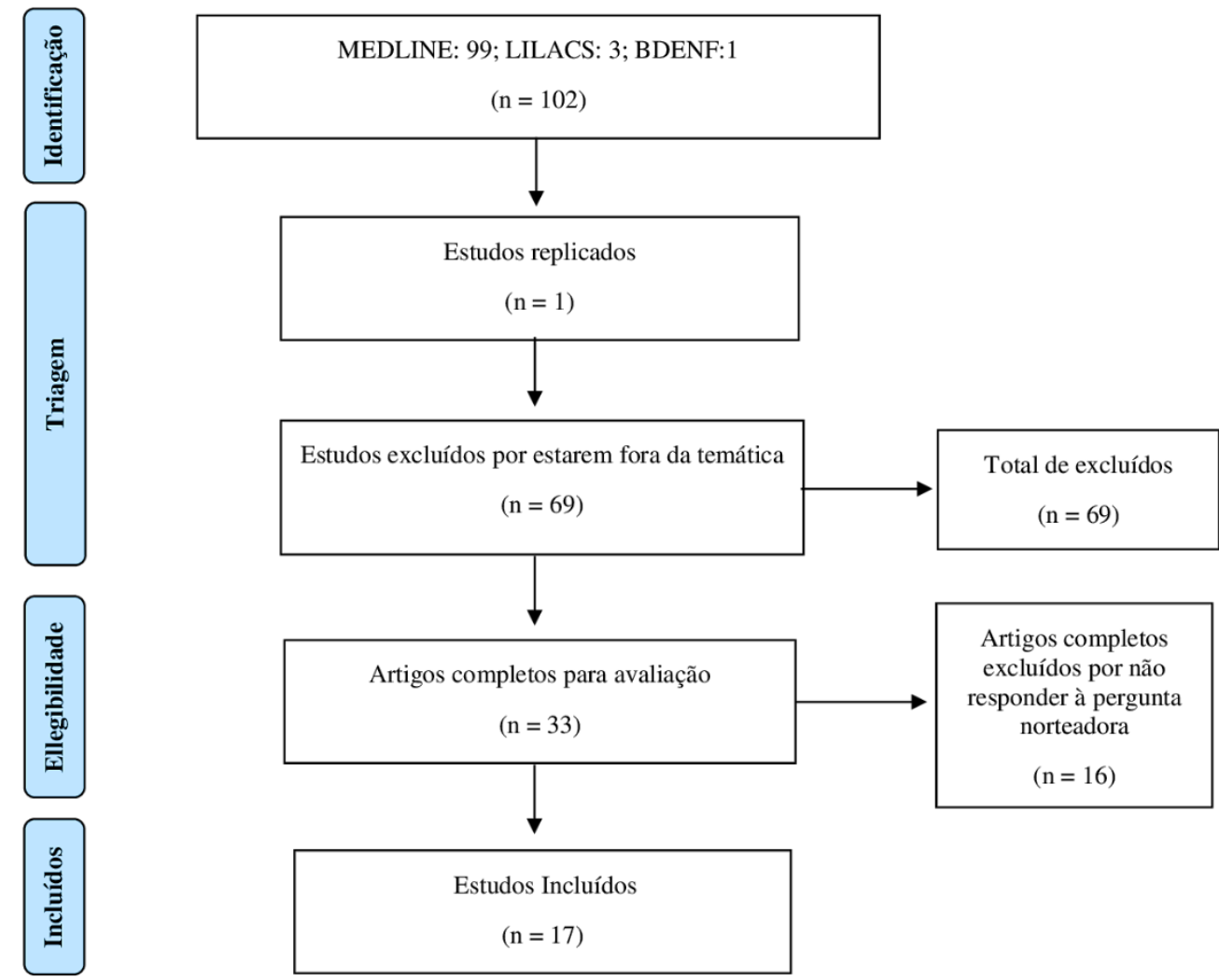

Estudos Incluídos

$$
(\mathrm{n}=17)
$$

\section{RESULTADOS E DISCUSSÃO}

Ao todo 17 artigos compuseram a amostra dessa pesquisa, sendo 16 indexados na base de dados MEDLINE e 1 na base de dados LILACS. Todos os artigos evidenciaram o impacto das mídias sociais perante a COVID-19, apresentando suas potencialidades e desafios. A síntese dos estudos selecionados segue detalhada no quadro 1 . 
Quadro 1. Caracterização dos estudos selecionados à revisão

$\begin{array}{cccc}\text { AUTORES } & \text { BASE DE } & \text { POTENCIALIDADES } & \text { DESAFIOS }\end{array}$

AHMAD, A. R., MURAD, H. R.

ARAVIND, S. R.,

TAN, S. G.;

WEE, H. L.

MEDLINE.

MEDLINE. Não evidenciado.

Disseminação do pânico.

Uso de mídias sociais para compreensão das narrativas e os sentimentos dos usuários.

Possibilitando ajuste no discurso das autoridades de saúde com intuito de aliviar o pânico durante a pandemia.

BASCH, C. H. et al. MEDLINE. Detém a presença e interação de muitos usuários.

\section{DONG, M.;}

ZHENG, J.

FAROOQ, A. et al. MEDLINE.

GAO, J. et al. MEDLINE.

KADAM, A. B. et al. MEDLINE.

LARSON, H. J.

MEDLINE.

LI, H. O. et al.

MEDLINE.

LIMA, D. L.

LOPES, M. A. A. A. M.;

MEDLINE.

BRITO, A. M.

LOPEZ, T. B. S. MEDLINE.

\begin{tabular}{l|l} 
NETO, M. et al. & LILACS; \\
BDENF
\end{tabular}

BDENF.

SAHOO, S. S;

SAHU, D. P.;

KANKARIA, A.

SEGURA, M. S. $\quad$ MEDLINE.

YASIR, A. et al. $\quad$ MEDLINE.
A mídia possui papel importante na divulgação de notícias relacionadas a crises de saúde pública.

A mídia possui papel importante nas avaliações de ameaças e de enfrentamento ao tentar entender o comportamento humano durante pandemias.

Não evidenciado.

As mídias sociais têm papel crucial na difusão da conscientização e conhecimento sobre saúde pública.

Não evidenciado.

Disseminação de conteúdos visuais e auditivos.

Coleta de informações relacionadas aos sintomas, rotas e interações por meio da mídia social.

Utilização das mídias sociais para comunicar atualizações constantes sobre a COVID-19.

Não evidenciado.

Não evidenciado.

A mídia social como o principal meio de comunicação da atualidade.

As mídias sociais como fonte de conhecimento para proteção à saúde.
Fake News.

Infodemia.

Não evidenciado.

Disseminação do pânico e informações de cunho duvidoso.

Excesso de notícias.

O papel altamente complexo da internet e a sobrecarga de informações.

\section{Infodemia.}

Fake News.

Fake News.

Propagação de informações de cunho duvidoso.

Fake News.

Fake News

Fake News.

Manter as pessoas calmas durante uma pandemia. 


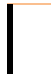 \\ YIN, F. et al. \\ MEDLINE. \\ As mídias sociais ocasionaram impactos importantes diante da pandemia da COVID-19. Nesta pesquisa, apresentam-se as categorias: potencialidades das mídias sociais e seus desafios ao enfrentamento da pandemia em curso. \\ Potencialidades das mídias sociais no enfrentamento da pandemia da COVID-19}

A mídia social como o principal meio de comunicação da atualidade.

As plataformas de mídia social podem ser usadas durante emergências de saúde pública para criar medidas direcionadas a prevenir e controlar a propagação da COVID-19.

Fonte: Elaborado pelos autores, 2020.
Entender como os tópicos sobre a COVID-19 se propagam nas mídias sociais.

Medir a atenção do público quanto aos tópicos mais acessados em relação a pandemia da COVID-19.
Em meio à pandemia, a internet possui papel complexo uma vez que tem amplitude de fontes de informações. Dentre elas, as mídias sociais, em que as pessoas adquirem e compartilham conhecimentos e experiências (FAROOQ; LAATO; ISLAM, 2020). Elas são responsáveis por interligar pessoas de qualquer lugar do mundo. De acordo com Lopez (2020), o não uso dessa ferramenta para a comunicação de informações e atualizações a respeito da COVID-19 é uma chance desperdiçada.

As mídias sociais podem ser utilizadas para o desenvolvimento de atividades educacionais, como estudo que revela o desenvolvimento de seminários de forma online para abordar assuntos relacionados a COVID-19. Além disso, através de mídias sociais podem ser realizadas coleta de informações, relacionadas aos sintomas, rotas e interações de pessoas que estão isoladas, sendo possível compreender a propagação do vírus e planejar estratégias de combate (LIMA; LOPES; BRITO, 2020).

Neste sentido, reconhece-se a potencialidade das mídias sociais para o enfretamento da COVID-19 porque permitem a rápida disseminação do conhecimento de diferentes localidades do mundo, sem restrições de barreiras geográficas. Uma estratégia recomendada para minimizar o contágio da doença foi o isolamento social. Esta estratégia consiste em uma separação para minimizar o contato entre indivíduos potencialmente infectados, saudáveis e com altas ou baixas taxas de transmissão (OLIVEIRA; LUCAS; IQUIAPAZA, 2020).

Com isso, as pessoas infectadas que estavam em isolamento social, puderam acessar mais as mídias sociais. Assim, reconhece-se que outra potencialidade proporcionada, pelas mídias sociais, para o enfretamento da COVID-19 foi o consumo de diversos conteúdos advindos destas plataformas. Embora, estudos destacam que o consumo destas informações foi desenfreado (YASIR et al, 2020). Estas plataformas proporcionam a liberdade de comunicação entre pessoas em tempos de pandemia, a disseminação de informações, por esses veículos, tornaram-se imprescindíveis para informar e orientar (SEGURA, 2020).

Mesmo com a propagação da estratégia de isolamento social a fim de conter o avanço da infecção viral, os casos de indivíduos acometidos pela doença, continuaram a aumentar. Gao, Q., et al (2020), concluíram, no seu estudo, que todas as pessoas estão vulneráveis a COVID-19. Contudo, os indivíduos que possuem comorbidades e homens de idade avançada possuem maiores possibilidades de desenvolverem sintomas graves da doença.

Assim, para o enfrentamento da COVID-19, medidas restritivas foram impostas por meio do distanciamento social que teve como objetivo diminuir o contágio, e consequentemente; a necessidade de internações em Unidades de Terapia Intensiva em curto espaço de tempo, mantendo a demanda de acordo com a capacidade assistencial do sistema de saúde (RAFAEL et al, 2020).

Com isso, a redução das interações entre os indivíduos também oportunizou o consumo pelas plataformas digitais (SOUSA JÚNIOR et al, 2020a). Outra potencialidade das mídias sociais ao enfrentamento da pandemia foi a possibilidade de lives, que são transmissões online e ao vivo por meio de perfis públicos sobre diversos assuntos. Em relação ao entretenimento foram desenvolvidos diversos projetos por cantores e patrocinadores através do Instagram e Youtube (SOUSA JÚNIOR et al, 2020b).

De acordo com Li et al (2020), o Youtube possui influência destacada em comparação com outras plataformas por proporcionar conteúdos visuais e auditivos. Os conteúdos vinculados nesta plataforma ajudaram à adesão de medidas de higiene e sanitárias por apresentar a descrição visual. Este recurso, pode ter facilitado a compreensão dos indivíduos para adoção 
destas estratégias de enfrentamento da pandemia. Contudo, sua pesquisa evidencia que mais de um quarto dos vídeos, com o maior número de visualização a respeito da COVID-19, foram pulicados nesta plataforma com informações duvidosas.

De acordo com o estudo de Aravind, Tan e Wee (2020), desde meados de fevereiro a março de 2020, os sentimentos em relação a pandemia da COVID-19 vêm sendo mais positivos. Comprovando que o monitoramento dos sentimentos das pessoas por meio das mídias sociais é um recurso interessante para ajudar na avaliação das ações de educação em saúde. Neste sentido, reconhece-se que as mídias sociais são importantes para o enfrentamento da pandemia em progresso. Além disso, parece que acompanham as transformações sociais da população.

\section{Desafios das mídias sociais no enfrentamento da pandemia da COVID-19}

Há estudos que apontam que o impacto das mídias sociais no enfrentamento da pandemia em curso, ainda perpassam desafios. Segundo Farooq, Laato e Islam (2020), a cibercondria e as informações exarcerbadas advindas da internet foram predominantes em pessoas que consumiam conteúdos de mídias sociais.

Os conteúdos publicados no Youtube, a respeito de orientações da COVID-19 que foram amplamente visualizados; parece não ter alcançado o objetivo de orientar sobre a prevenção da doença. Por isso, além de produzir conteúdo com informações e orientações relevantes, é necessária a avaliação dos efeitos (BASCH et al, 2020). Neste sentido, deve-se avaliar à adequação dos conteúdos às faixas etárias e possibilidade para compreensão de pessoas com limitações e/ou deficiências.

Outro desafio relacionado ao impacto das mídias sociais para o enfrentamento da COVID-19 foram as Fake News. Verificou-se que com o aumento das notícias acerca da COVID-19 ocorreu um aumento de notícias falsas. As principais Fake News eram relacionadas à transmissão e sobrevivência do vírus (LOPEZ, 2020; KADAM; ATRE, 2020).

As Fake News são recebidas através de smartphones por meio de canais como Facebook, Twitter, WhatsApp, YouTube e Instagram e, são veiculadas às redes sociais de forma rápida e multiplicada (LIMA; LOPES; BRITO, 2020). Essa disseminação de desinformações sobre a pandemia é conceituada segundo a Organização Mundial da Saúde (OMS) como infodêmico (SEGURA, 2020).

Esses acontecimentos ocasionaram prejuízos à saúde mental dos indivíduos e podem ter os confundido, causando interferências nos comportamentos e na saúde da população. Isso foi percebido quando houve a busca intensa pela compra de equipamentos de proteção individual (EPI), como as máscaras cirúrgicas, provocando o uso indevido de EPIs, resultando em limitações e até escassez, para abastecer os serviços de saúde à utilização pelos profissionais de saúde da linha de frente (KADAM; ATRE, 2020). Neste contexto, observase os desafios, no controle da pandemia, por conta da disseminação de informações equivocadas em saúde para a população.

Outro desafio relacionado ao impacto das mídias sociais para o enfrentamento da COVID-19 parece ter sido o aumento do número de casos de pessoas com problemas de saúde mental. Gao, J. et al (2020), informam que o aumento do número de casos de pessoas com problemas de saúde mental durante a pandemia da COVID-19 é real e que estratégias governamentais necessitam direcionar atenção a este contexto. Os sentimentos de estresse e a ansiedade ganharam proporções preocupantes. Indivíduos com condições mentais pré-existentes, como ansiedade e transtorno obsessivo compulsivo apresentaram pioras em sua condição clínica (SAHOO; SAHU; KANKARIA, 2020).

Os desafios relacionados ao impacto das mídias sociais frente à pandemia da COVID-19, para as autoridades de saúde, é que algumas informações são claramente falsas e prejudiciais. No entanto, outras são menos claras e difíceis de definir e refutar (LARSON, 2020). Essas informações podem utilizar nomes de autoridades da área do conhecimento articuladas às instituições renomadas, mas com linguagem acessível para leigos. Estes a consomem e compartilham sem a devida averiguação da fidelidade das informações (MERCEDES-NETO, 2020).

As notícias sobre a pandemia da COVID-19 geraram ansiedade e pânico. As mensagens instantâneas colaboram com a disseminação dessas informações. Uma pesquisa realizada com usuários de mídia social aponta que existe uma relação entre o pânico em torno da COVID-19 e as mídias sociais na região do Curdistão, no Iraque (DONG; ZHENG, 2020; AHMAD; MURAD, 2020).

Neste sentido, os estudos avaliados na presente pesquisa apresentaram recomendações para diminuir o impacto negativo das mídias sociais na saúde dos sujeitos. As recomendações incluiram: estimular a criticidade entre a população sobre a interpretação dos relatórios não oficiais; intervenções estratégicas que devem motivar às pessoas a adotarem medidas de saúde que considerem a redução da sobrecarga de informações, por meio da estruturação clara e comunicação de informações confiáveis (DONG; ZHENG, 2020; FAROOQ; LAATO; ISLAM, 2020; YASIR, 2020).

Outras recomendações foram que as instituições de saúde pública podem combater a desinformação atualizando frequentemente os principais fatos em sua 
mídia oficial (DONG; ZHENG, 2020). Além disso, o governo e as organizações não governamentais devem começar a estudar a atenção do público em relação à epidemia da COVID-19, nas plataformas de comunicação, a fim de projetar estratégias de comunicação eficazes (ZHAO et al, 2020; YIN, 2020). Assim, compreende-se a existência de desafios na usabilidade de mídias sociais frente ao enfrentamento da pandemia da COVID-19, causando impacto negativo frente a vida das pessoas.

Esta pesquisa apresenta como limitação o fato de que ainda não é possível dimensionar todas as implicações dos impactos das mídias sociais no enfrentamento da pandemia de COVID-19, pois eram importantes mais pesquisas nesta temática para verificações de outras evidências. Contudo, o estudo contribuiu para fortalecer a necessidade de ampliar pesquisas com este tema.

\section{CONCLUSÃO}

O estudo acerca das evidências dos impactos das mídias sociais para os usuários no enfrentamento da pandemia da COVID-19 revelou que há potencialidades e desafios. As potencialidades de impactos das mídias sociais no enfrentamento da pandemia da COVID-19 foram possibilidade de rápido compartilhamento de notícias, atualizações e orientações, adesão de diferentes públicos, coleta de informações, compreensão da narrativa dos usuários por meio de recursos visuais e auditivos.

Os desafios que impactam às mídias sociais no enfrentamento da pandemia da COVID-19 foram principalmente, a sobrecarga de informações e a disseminação de Fake News acarretando como consequência o desenvolvimento ou agravamento de distúrbios psicológicos. Além disso, conteúdos com orientações a respeito da COVID-19 aparentemente não alcançaram resultados relevantes, tornando notória a necessidade de avaliação dos efeitos produzidos pelos materiais compartilhados.

Entende-se que estes veículos de informações possuem potencial significativo de orientar e influenciar as pessoas. Por isso, é um aspecto positivo em ser agregados às plataformas, mesmo diante dos desafios evidenciados. Sugere-se que novos estudos sobre a temática sejam realizados, pois esses são o principal meio de comunicação da atualidade.

\section{AGRADECIMENTOS}

As autoras agradecem a Pró-Reitoria de Extensão (PROEX) da Universidade Regional do Cariri (URCA) e ao Programa de Bolsas Universitárias da URCA (PBU) pelas bolsas de extensão.

\section{REFERÊNCIAS}

AHMAD, A. R.; MURAD, H. R. The Impact of Social Media on Panic During the COVID-19 Pandemic in Iraqi Kurdistan: Online Questionnaire Study. J Med Internet Res., v. 22, 2020. DOI: https://dx.doi.org/10.2196/19556.

ARAVIND, S. R.; TAN, S. G.; WEE, H. L. Measuring the Outreach Efforts of Public Health Authorities and the Public Response on Facebook during the COVID-19 Pandemic in Early 2020: A CrossCountry Comparison. Journal of Medical Internet Research, v. 22, 2020. DOI: https://doi.org/10.2196/preprints.19334.

BASCH, C. H. et al. Preventive Behaviors Conveyed on YouTube to Mitigate Transmission of COVID-19: CrossSectional Study. JMIR Public Health Surveill, v. 6, n. 2, p. 1-6, 2020. DOI: https://dx.doi.org/10.2196/18807.

DONG, M.; ZHENG, J. Letter to the editor: Headline stress disorder caused by Netnews during the outbreak of COVID-19. Health Expectations, v. 23, p. 259-260, 2020. DOI: https://doi.org/10.1111/hex.13055.
FAROOQ, A.; LAATO, S.; ISLAM, A. N. Impact of Online Information on Self-Isolation Intention During the COVID-19 Pandemic: Cross-Sectional Study. J Med Internet Res, v. 22, n. 5, 2020. DOI: 10.2196/19128.

FIOCRUZ. Por que a doença causada pelo novo vírus recebeu o nome de Covid-19?. 2020. Disponível em: $<$ https://portal.fiocruz.br/pergunta/por-que-doencacausada-pelo-novo-virus-recebeu-o-nome-de-covid-19>. Acesso em: 16 jul. 2020.

FRANÇA, T.; RABELLO, E. T.; MAGNAGO, C. As mídias e as plataformas digitais no campo da Educação Permanente em Saúde: debates e propostas. Saúde debate, Rio de Janeiro, v. 43, p. 106-115, ago. 2019. DOI: https://doi.org/10.1590/0103-11042019s109.

GAO, J. et al. Mental health problems and social media exposure during COVID-19 outbreak. PLoS ONE, v. 15, 2020.

DOI:

https://doi.org/10.1371/journal.pone.0231924.

GAO, Q. et al. The epidemiological characteristics of 2019 
novel coronavirus diseases (COVID-19) in Jingmen,Hubei,China. medRxiv, 2020. DOI: https://doi.org/10.1101/2020.03.07.20031393.

SOUSA JÚNIOR, J. H. S. et al. Da Desinformação ao Caos: uma análise das Fake News frente à pandemia do Coronavírus (COVID-19) no Brasil. Cadernos de Prospecção, v. 13, n. 2, p. 331-346, 2020a. DOI: http://dx.doi.org/10.9771/cp.v13i2\%20COVID-19.35978.

SOUSA JÚNIOR, J. H. S. et al. "\#FIQUEEMCASA E CANTE COMIGO”: ESTRATÉGIA DE ENTRETENIMENTO MUSICAL DURANTE A PANDEMIA DE COVID-19 NO BRASIL. Boletim de Conjuntura (BOCA), v. 2, n. 4, 2020b. DOI: http://dx.doi.org/10.5281/zenodo.3752276.

KADAM, A. B.; ATRE, S. R. Negative impact of social media panic during the COVID-19 outbreak in India. Journal of Travel Medicine, v. 27, n. 3, 2020. DOI: 10.1093/jtm/taaa057.

LARSON, H. J. Blocking information on COVID-19 can fuel the spread of misinformation. Nature, v. 580, 2020. DOI: 10.1038 / d41586-020-00920-w.

LI, H. O. et al. YouTube as a source of information on COVID-19: a pandemic of misinformation?. BMJ Global Health, v. 5, ed. 5, 2020. DOI: https://dx.doi.org/10.1136/bmjgh-2020-002604.

LIMA, D. L.; LOPES, M. A. A. A. M.; BRITO, A. M. Social media: friend or foe in the COVID-19 pandemic? Clinics, São Paulo, v. 75, 2020. DOI: https://doi.org/10.6061/clinics/2020/e1953.

Capacity. Journal of Public Health Management and Practice, v. 26, ed. 4, p. 384-386, 2020. DOI: https://dx.doi.org/10.1097/PHH.0000000000001196.

MENDES, K. D. S.; SILVEIRA, R. C. C. P.; GALVÃO, C. M. Uso de gerenciador de referências bibliográficas na seleção dos estudos primários em revisão integrativa. Texto \& Contexto Enfermagem, v. 28, 2019. DOI: https://doi.org/10.1590/1980-265x-tce-2017-0204.

MOHER, D. et al. Preferred Reporting Items for Systematic Reviews and Meta-Analyses: The PRISMA Statement. PLoS Med., v. 6, p. 1-6, jul. 2009. DOI: https://doi.org/10.1371/journal.pmed.1000097.

NETO, M. et al. Fake news no cenário da pandemia de COVID-19. Cogitare enferm., v. 25, 2020. DOI: http://dx.doi.org/10.5380/ce.v25i0.72627.
OLIVEIRA, A. C.; LUCAS, T. C.; IQUIAPAZA, R. A. O que a pandemia da COVID-19 tem nos ensinado sobre adoção de medidas de precaução? Texto \& Contexto

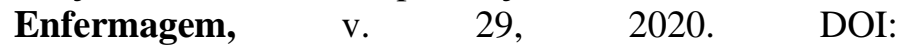
https://doi.org/10.1590/1980-265x-tce-2020-0106.

OLIVEIRA, C.; MOURA, S. P.; SOUSA, E. R. Tic's na Educação: A utilização das tecnologias da informação e comunicação na aprendizagem do aluno. Pedagogia em Ação, v. 7, n. 1, p. 75-95, 2015. Disponível em: <http://periodicos.pucminas.br/index.php/pedagogiacao/a rticle/view/11019>. Acesso em: 16 jul. 2020.

RAFAEL, R. M. F. et al., Epidemiologia, políticas públicas e pandemia de Covid-19: o que esperar no Brasil? Rev enferm UERJ, v. 28, 2020. DOI: https://doi.org/10.12957/reuerj.2020.49570.

SAHOO, S. S.; SAHU, D. P.; KANKARIA, A. Misinfodêmico: O calcanhar de Aquiles no combate à pandemia do COVID-19 em uma perspectiva indiana. Monaldi Archives for Chest Disease, v. 90, p. 330-332, 2020.2 DOI: https://doi.org/10.4081/monaldi.2020.1405.

SILVA, V. A.; SOARES, M. H. F. B. O uso das tecnologias de informação e comunicação no ensino de Química e os aspectos semióticos envolvidos na interpretação de informações acessadas via web. Ciênc. educ. (Bauru), Bauru , v. 24, n. 3, p. 639-657, set. 2018

DOI: https://doi.org/10.1590/1516-731320180030007.

SEGURA, M. S. Con alerta pero sin pánico. El rol de los medios durante la pandemia. Revista de la Facultad de Ciencias Médicas de Córdoba, v.77, n. 1, p. 55-58, 2020. DOI: https://doi.org/10.31053/1853.0605.v77.n1.28066.

WORLD HEALTH ORGANIZATION. WHO DirectorGeneral's opening remarks at the media briefing on COVID-19 - 11 March 2020. Disponível em: $<$ https://www.who.int/dg/speeches/detail/who-directorgeneral-s-opening-remarks-at-the-media-briefing-oncovid-19---11-march-2020>. Acesso em: 16 jul. 2020.

YASIR, A. et al. Modeling Impact of Word of Mouth and E-Government on Online Social Presence during COVID19 Outbreak: A Multi-Mediation Approach. Int. J. Environ. Res. Public Health, v. 17, 2020. DOI: https://doi.org/10.3390/ijerph17082954.

YIN, F. et al. COVID-19 information propagation dynamics in the Chinese Sina-microblog. Mathematical Biosciences and Engineering, v. 17, n. 3, p. 2676-2692, 
2020. DOI: http://dx.doi.org/10.3934/mbe.2020146.

ZHAO, Y. et al., Chinese Public's Attention to the COVID-19 Epidemic on Social Media: Observational Descriptive Study. J Med Internet Res, v. 22, n. 5, 2020. DOI: http://doi.org/10.2196/18825. 